\title{
Für Deutschland neue oder seltene Rüsselkäfer.
}

Stasiodis (Sciaphilus) parvulus Fab. aus Italien, Südfrankreich und Dalmatien bekannt, wurde von mir am 7. Juni 1896 auf dem Kaiserstuhl zahlreich auf einer lichten Waldstelle von Genista germanica gestreift. Die Beschuppung variirt von hellgrün bis blafsgrün mit schwachem röthlichem Schimmer.

Barypithes montanus Chevr., im südlichen Schwarzwald nicht selten, findet man schon im ersten Frühjahr durch Aussieben von Moos und Laub an Waldrändern. Bei einer grofsen Anzahl in frischem und reinem Zustande befindlicher Thiere tragen alle Punkte des Halssch. sowie der Fld.-Streifen ein feines kurzes, etwas vom Grunde abgehobenes Härchen, ebenso befindet sich auf den $\mathrm{Z}$ wischenräumen der Decken eine Reihe weit von einander abstehender gleicher Härchen, die sehr hinfällig sind und leicht abgerieben werden. Die Punktirung des Halssch. ist nicht sehr dicht, mehr zerstreut; die mehr oder weniger deutliche Mittellinie ist unpunktirt und nicht behaart, die Haare sind alle gegen diese Mittellinie zu gerichtet. Das Halssch. ist kaum breiter als lang, bei den meisten vorliegenden Ex. so lang als in der Mitte breit; Hr. Seidlitz in seiner Monogr. der Otiorhynchiden s. str. p. 69 und Hr. Stierlin in der Bestimmungstabelle XIII, 2, p. 37, bezeichnen dasselbe "breiter als lang"; dafs beide Autoren die Fld. als „kahl oder selten mit einzelnen ganz dünnen Härchen besetzt"s angeben, lälst die Vermuthung aufkommen, dafs ihnen alte, abgeriebene Ex. vorgelegen haben.

Rhytidosomus dentipes Reitt., D. E. Z. 1885, p. 369, aus Kärnthen beschrieben, klopfte ich am 8. Juni 1895 bei Kehl in der Nähe des Rheinufers von Weidengebüsch. Das einzige Ex. hat Hrn. Reitter vorgelegen und unterscheidet sich von globulus hauptsächlich durch kürzere Gestalt, durch aufgerichtete Börstchen auf den Deckenzwischenräumen und durch ganz schwarze Beine. Im Schilsky'schen Catalog fehlt diese Art.

Ceuthorhynchus Pandellei Bris. bis jetzt nur aus den Pyrenäen bekannt, findet sich in Baden im Schwarzwald am südlichen Abhange des Feldberges. Diese schöne Art wurde von Hrn. Förster und mir am 28. Juni 1896 von Nasturtium officinale in Anzahl gestreift; ein einzelnes Stück fand ich ebendaselbst im Jahre 1894 auf Aconitum napellus. Die Beschreibung von Brisout, sowie diejenige, die Hr. Weise in D. E. Z. 1883, p. 330, von diesem Thiere giebt, pafst genau auf vorliegende 7 Stücke; charakteristisch ist die lange und schmale Gestalt der $₫$, während die $q$ viel breiter sind.

F. Hartmann. 


\section{$2 \mathrm{BHL}$ Biodiversity Heritage Library}

Hartmann, F. 1897. "Für Deutschland neu oder seltene Rüsselkäfer." Deutsche entomologische Zeitschrift 1897(1), 203-203.

https://doi.org/10.1002/mmnd.48018970140.

View This Item Online: https://www.biodiversitylibrary.org/item/103831

DOI: https://doi.org/10.1002/mmnd.48018970140

Permalink: https://www.biodiversitylibrary.org/partpdf/235698

\section{Holding Institution}

Harvard University, Museum of Comparative Zoology, Ernst Mayr Library

\section{Sponsored by}

Harvard University, Museum of Comparative Zoology, Ernst Mayr Library

\section{Copyright \& Reuse}

Copyright Status: Public domain. The BHL considers that this work is no longer under copyright protection.

This document was created from content at the Biodiversity Heritage Library, the world's largest open access digital library for biodiversity literature and archives. Visit BHL at https://www.biodiversitylibrary.org. 